University of Nebraska - Lincoln

DigitalCommons@University of Nebraska - Lincoln

2018

Entrepreneurship Everywhere: Across Campus, Across

Communities, and Across Borders

Jeffrey S. Hornsby

Jake G. Messersmith

Matthew Rutherford

Sharon Simmons

Follow this and additional works at: https://digitalcommons.unl.edu/managementfacpub

Part of the Business Administration, Management, and Operations Commons, Management Sciences and Quantitative Methods Commons, and the Strategic Management Policy Commons

This Article is brought to you for free and open access by the Management Department at

DigitalCommons@University of Nebraska - Lincoln. It has been accepted for inclusion in Management Department Faculty Publications by an authorized administrator of DigitalCommons@University of Nebraska - Lincoln. 


\title{
Entrepreneurship Everywhere: Across Campus, Across Communities, and Across Borders
}

\author{
Jeffrey S. Hornsby, Jake Messersmith, \\ Matthew Rutherford, \& Sharon Simmons
}

Jeffrey S. Hornsby is the Henry W. Bloch/Missouri Endowed Chair of Entrepreneurship in the Henry W. Bloch School of Management at the University of Missouri-Kansas City.

Jake Messersmith is Associate Professor of Management in the College of Business at the University of Nebraska-Lincoln.

Matthew Rutherford is Associate Professor and Johnny D. Pope Chair in Entrepreneurship in the School of Entrepreneurship at Oklahoma State University.

Sharon Simmons is Assistant Professor of Global Entrepreneurship and Innovation in the Henry W. Bloch School of Management at the University of Missouri-Kansas City.

Correspondence: J. S. Hornsby, Global Entrepreneurship, Bloch School of Management, University of Missouri, Kansas City, MO 6411o.Email: hornsbyj@umkc.edu.

This paper introduces the theme of this special issue related to "Entrepreneurship Everywhere: Across Campus, Across Communities, and Across Borders." We explore three critical points as we set up the accepted articles for the special issue. First, if we are everywhere are we anywhere? Second, we focus on the importance of collaboration. Third, we discuss the importance of strategically planning on how your efforts intervene or integrate into the wider ecosystem.

Published in Journal of Small Business Management 56:1 (2018), pp. 4-10.

doi: $10.1111 /$ jsbm.12386

Copyright 2018 John Wiley. Used by permission. 
7 ntrepreneurship is everywhere. A search of the term "entrepreL neurship" on Google yields 132 million results. By comparison a search on "strategic management" yields a mere 17.2 million results. Despite the highly unscientific nature of this comparison, the results shine the light on the tremendous interest and growth in entrepreneurship and entrepreneurs. The job creation potential of small businesses and entrepreneurial firms has captured the attention of politicians from across the globe and the ideological spectrum, who frequently hale the benefits of entrepreneurial activity. Citing work by Tornatzky and Rideout (2014), the Kauffman Foundation's (2015) "State of Entrepreneurship" address indicates that entrepreneurship programs, both curricular and noncurricular, are the fastest-growing programs on college campuses. While many large corporations are villainized, entrepreneurs and small businesses are generally held in high regard and lionized in many instances.

Further, interest and growth in the topic of entrepreneurship is unbound by geography or academic discipline. Across many university campuses it is common to find multiple programs and centers dedicated to fostering and growing entrepreneurship. Programs as diverse as engineering, music, pharmacy, agriculture, art, and law are all focusing on helping their students to both engage in entrepreneurial thinking and activity. While the business school remains a key component of the entrepreneurial ecosystem on campuses across the globe, the diversity of programs has grown dramatically.

This special issue seeks to highlight this expansive growth by including a diverse set of articles that point to the explosive growth of entrepreneurship and entrepreneurship programing around the world, within our communities and on college campuses. We will briefly preview each of the contributions below, but first we highlight three critical and related questions of the growth of entrepreneurship. First, if entrepreneurship is everywhere, is it truly anywhere? Second, as entrepreneurship continues to be an emphasis across levels of federal, state, and local government and as diverse university entities continue to seek to spark entrepreneurial activities, how is this best managed? Third, how is the entrepreneurial ecosystem affected by the tremendous investment and enhanced focus of universities and government entities in trying to engineer entrepreneurship? 


\section{Everywhere, but Anywhere?}

The term entrepreneurship is leveraged by many across campuses, private industry, and public agencies. It is certainly in vogue, though it is far from a trend or a fad. In this special issue, Kuratko and Morris trace a brief outline of the history of entrepreneurship programs and the manner in which such programs have developed over time. As these authors note, the history and development of entrepreneurship on college campuses has lacked a clear strategic orientation and many programs and centers have been created with little understanding of the goals that they are expected to achieve. This disjointed growth on campus is matched by well-intended efforts by public agencies and policy makers determined to deliver economic development and growth to their constituents. Different audiences with different objectives define entrepreneurship in unique ways. With such disparate origins and goals all coming under the label of "entrepreneurship," the threat exists that the term will begin to lose its meaning. If entrepreneurship is everything, it risks being nothing.

Kuratko and Morris highlight this fact and draw readers back to the important definitions of entrepreneurship that have been developed in the field. These definitions help to set boundary conditions and set priorities for the field. Kuratko and Morris build on these basic definitions to outline 10 of the fastest-growing areas of development in scholarship on entrepreneurship. These areas ranging from opportunity recognition to social entrepreneurship to corporate entrepreneurship serve to outline some of the directions in which the field has begun to advance.

The diversity of these research streams highlights the fact that the reach of entrepreneurship is broad and the possibilities are rich. However, the critical importance of starting from a proper definition of what entrepreneurship is and what it is not is salient to the vitality of the field. Indeed, the prescription to "think like an entrepreneur" applies to an endless number of contexts, provided one has the proper definition of the entrepreneurial mindset to apply. With a common set of roots established, the field of entrepreneurship can branch in many profitable directions. 
Of course, one of the primary ways in which entrepreneurship is defined and advanced is in delivering the message of an entrepreneurial mindset to future generations.

In this issue, Kuratko and Morris pay special attention to building an understanding of the future trajectory of entrepreneurship by focusing on the processes, delivery, structure, and content involved in teaching the entrepreneurial mindset to students. This portion of the article by Kuratko and Morris lays a strong foundation and framework for the future of entrepreneurship education. As students continue to hunger for skills and training it is important that universities and other entities be prepared to equip and empower students with the knowledge and opportunities they need.

As Kuratko and Morris stress, this preparation involves teaching students the important competencies necessary to think and act as an entrepreneur. It also involves a greater emphasis on applied and co-curricular activities. Indeed, entrepreneurship is well positioned to take advantage of university trends toward experiential learning. While a certain element of textbook learning will continue to be valuable, strong entrepreneurship programs will continue to provide students with the opportunity to think and behave entrepreneurially. Kurtako and Morris also stress the need for academic entrepreneurs who not only teach students and provide these opportunities, but they also model them in their own roles on campus. Managing cross-disciplinary activities in the contemporary university environment is a challenge, which requires those of us involved in the enterprise to display the same mindset that we espouse. This mindset requires unique and innovative approaches to getting activities done on campus, developing programs and securing sustainable funding models using a mix of public and private sources.

\section{Cross-Entity Collaboration}

As highlighted above, entrepreneurship has become a part of the lexicon of a diverse set of public and private entities. There are notable private institutions dedicated to the service of entrepreneurship. There are a host of government programs at local, state, and federal levels dedicated to producing entrepreneurship. There are economic 
development offices focusing on spurring entrepreneurship. Within many large universities there are now multiple offices and staff members dedicated to the study, education and advancement of entrepreneurship. While all of these entities have slightly different charges, the intended outcome is shared. Whether the focus is on teaching computer science students how to produce marketable "apps," hosting legal clinics in the law school to support new business formation, teaching pharmacists to think more like entrepreneurs, helping to revitalize rural communities or transferring scientific discoveries into marketable business models, all of these entities share a common goal-higher levels of business start-up and economic growth.

Yet despite the common goal there is a tendency to remain in one's disciplinary silo. Differing communities and disparate funding sources lead these entities to focus on their own "turf." Each entity has a charge to prove its own worth, which may lead to duplication of effort, crossentity competition and less efficient operations. As a result, campuses and communities may not be receiving the greatest potential benefit from their resource investments. The problems are easy to spot; the solutions are harder to find. We do not presuppose to know the answers here, but we point to a few key factors to consider.

First, we believe it is imperative to focus on the shared purpose and goal. Paths and metrics may differ, but the ultimate goal across communities and campus entities is the same. We are all seeking to promote entrepreneurship and to open doors to economic opportunity. As basic as this sounds, frequently underscoring the shared vision and purpose is likely a necessary exercise in boosting entrepreneurial activity.

Second, it might be worthwhile to consider not only the value proposition of each individual entity, but also the shared value proposition of the system. Local entrepreneurs and students can benefit from the activities of the entire system, not simply from those of a single entity. Having multiple groups collaborate on pitch competitions, business plan competitions, weekend start-up activities, accelerators, and other programing will be to the benefit of all involved. Indeed, this is often the goal, but it has proven elusive at many institutions. Taking the time to sit down and work out a shared value proposition and a coordinated set of activities may pay dividends. This rings true for community-based efforts as well. Pooling resources to create shared 
programs may prove useful for enhancing the quality of entrepreneurship programing, even if doing so reduces the quantity of activity.

Third, we believe that we should resist efforts to mechanistically centralize entrepreneurial efforts. While centralization may prove to be the most efficient organizational form, it will likely quell the organic processes that underscore entrepreneurial activity. There is a temptation from business schools and elsewhere, to bring all of the various activities aimed at entrepreneurship under "one tent." Centralizing the process might allow for resources to be allocated more efficiently and will reduce duplication, but will also be met with tremendous resistance. The more organic approach may be more desirable, where information is shared across silos, programing is jointly executed and entrepreneurship continues to be championed from various places on campus and in the community. If there is one central administrative oversight area for entrepreneurship it must have the awareness not to stifle the organic nature of entrepreneurial activity.

Finally, while entrepreneurship is promoted and supported by diverse entities, it is important that it also retains its distinct status as a field of study and academic discipline. The frameworks and knowledge generated by scholars in the field ought to help inform crosscampus and crossborder entrepreneurial activity. While entrepreneurial activity is everywhere, it is important that entrepreneurship retain its unique status as an academic discipline and field of study. Without retaining its uniqueness, the field runs the risk of devolving into a buzzword with little shared meaning.

\section{Intervening in the Ecosystem}

When thinking about entrepreneurship being everywhere, we as researchers, educators, and administrators must think very critically about our optimal role in promoting entrepreneurship to be "everywhere." There are many ways in which we can engage in this promotion. As researchers, for example, we document best practices and create new ways forward for entrepreneurs. In addition, we create knowledge that we, in turn, use as educators to train entrepreneurs. We train them to start businesses that will be at least viable, and ideally be generators of societal wealth. As administrators, we develop 
programs, centers, and institutes with the goal of further training entrepreneurs and informing research. But one thought that likely seldom crosses our minds as advocates of entrepreneurship is "how much should we advocate." Or stated differently, is there a danger in too much advocacy.

If we can extend the "ecosystem" metaphor, then we can draw upon some of what we know from biology (cf., Hobbs et al. 2011). This literature, while certainly more nuanced and complex than we can explore here, is highly suggestive that outside intervention into an ecosystem often has unintended and sometime deleterious effects. For example, the introduction of nonindigenous species into a certain context has devastated indigenous species in that context.

At a macro level it seems prudent to ask what the effects are of this enhanced focus on entrepreneurship on the overall ecosystem. Can we engage in social engineering to produce greater levels of entrepreneurship or, despite the best of intentions, are we circumventing market forces in such a way that we may produce unintended consequences? The answers to such questions will evolve over time, but it is worth considering the fact that our interventions may have an effect on the market forces that have traditionally helped to drive and sift entrepreneurial activity. For instance, universities are now pouring significant resources into building incubators and providing start-up funding for both student and community entrepreneurs.

Many such initiatives are reported on in the papers in this special issue. For instance, Guerrero et al. reports on the initiatives of a network of entrepreneurial universities (Guerrero, Urbano, Cunningham and Gajon, 2017). Indeed, some incubators are even pairing student teams up with mentors (i.e., Ahsan, Zheng, DeNoble and Musteen, 2017). By handing these would-be entrepreneurs resources that they would typically have to earn in the market, is there the potential that we are short-circuiting market forces? Will these efforts lead to more initial starts, but fewer "battle tested" sustainable enterprises? At some level building a business model that will attract financing, seeking, and securing strong mentorship and even finding physical space is part of the market-born elements of the entrepreneurial process that helps to bring forward entrepreneurs with strong and sustainable business models. What effect does speeding up this process and skipping traditional steps have on the ultimate outcome? To be 
sure, market forces will eventually separate businesses that succeed from those that do not, but what effect are our interventions having on these processes? Are we building businesses and entrepreneurs capable of withstanding the competitive forces they will face?

In posing these questions, we are not advocating for ending such programs, nor are we seeking to throw artificial road blocks in the path of the entrepreneurial process. We are decidedly "pro-entrepreneurship." We are simply pointing to the fact that many of the traditional elements of the process that entrepreneurs have had to earn are now being given in an effort to create more and better businesses. Removing unnecessary obstacles to entrepreneurial opportunity is valuable, but short-circuiting market processes may not be. A field that once was predicated on the organic processes of competition and "creative destruction" (Schumpeter 1942) is now the target of social engineers. It bears consideration and observation to ensure that our best efforts to support and enhance entrepreneurial outcomes, do not become snares to the development of strong and sustainable businesses.

We must be responsible in our interventions and work to fully consider the multitude of systems and subsystems existing within the ecosystem. In addition, we must monitor as closely as possible, the impact of our designed intervention. As scholars, this has not always been our strength. We seem to be excellent at designing programs (e.g., incubators, accelerators, minors), but less interested in charting the performance of these programs. Moreover, we must be willing to withdraw an intervention if the outcome data is negative. As an example, our interventions thus far have met with equivocal results.

Perhaps, uncomfortably, we have yet to see impressive performance from incubators or accelerators (Fetsch 2015). As researchers we know far too little about ecosystems and their components, particularly accelerators and incubators.

If we embrace the fact that the market is the most efficient mechanism for aligning and distributing entrepreneurial efforts, then we must be willing to admit that any tampering with the market may result in something less than efficient distribution. Clearly, the crux of the issue here is the presence of "market failures."

Shane addressed this issue in 2009 when he cautioned policy makers against picking winners. Again, all of us would likely be offended if we were accused of picking winners with regard to our students' 
ventures, but unless all of these students receive the exact same benefits in the exact same way, we are helping some and not others. More vividly, in programs such as business plan competitions, we are literally picking winners. There is some assumption that we know which ventures will fail and which will succeed.

As Baumol (1990) pointed out some time ago, the most impactful entrepreneurial ecosystem interventions likely involve changing the "rules of the game," which can be loosely characterized as decisions around government policy. Interestingly, relatively little of our efforts as educators and scholars is dedicated to understanding and influencing these issues. Many of the impediments that we are trying to shield our students from are not market impediments, but policy impediments (i.e., rules of the game). These could be removed far easier with the stroke of a pen.

\section{What Are the Articles in This Special Issue?}

In addition to this introductory article there are eight excellent articles that fit the theme of the special issue in many ways. Short summaries of the important points in each article are presented here but you are encourage to read some informative works covering topics such as social entrepreneurship, mentoring, passion, culture, crosscampus entrepreneurship programs, determinants of start-up activity and an investigation into the determinants of quality entrepreneurship research.

Examining the Future Trajectory of Entrepreneurship by Donald F. Kuratko and Michael H. Morris.

As discussed earlier in this article, Kuratko and Morris challenge entrepreneurship educators and support organizations to identify specific missions and goals for their activities. They specifically argue that we cannot be all things to all people and determining the role of our efforts in the university and community entrepreneurial ecosystems is critical to the sustainability of our programs and their ultimate impact. Additionally, they advocate for six major trajectories for entrepreneurship education: 
(1) Having a clear purpose for why we teach entrepreneurship.

(2) Developing a core entrepreneurship curriculum to provide a common knowledge base for students.

(3) Teaching experientially using delivery mechanisms that enhance engagement and experimentation.

(4) Build an acceptable structure for the administration and delivery of entrepreneurship programs that fosters development of exciting programing.

(5) Identify key metrics to justify the resources invested in entrepreneurship programs. We are challenged to develop more relevant metrics than what we traditionally use in academic settings.

(6) Those selected for leadership of academic entrepreneurship programs should have academic stature, a clear vision and the ability to engage all disciplines from across the university.

Kuratko and Morris end with the concern that if we do not follow most of the suggestions they make we are in danger of losing the legitimacy academic entrepreneurship programs that we fought so hard for in the last 25 years.

\section{Where Change Happens: Community-level Phenomena in Social} Entrepreneurship Research by G. T. Lumpkin, Sophie Bacq, and Robert J. Pidduck.

Lumpkin, Bacq, and Pidduck advance the understanding of social entrepreneurship activities by utilizing a community-level of analysis. They make that claim that we need more research to understand the "social" in social entrepreneurship. Using a typology based on the UNESCO framework, they investigate social change in four types of communities; geographical communities, communities of interest or solidarity, communities of identity and intentional communities. Specifically, they wanted to understand the relationships between the type of community and four types of wealth creation: physical capital, financial capital, human capital, and social capital. They reviewed 49 refereed articles and 54 case studies from leading publications. Their results indicate that all four types of communities are important and they provide detailed descriptions of these relationships. 
Recognizing Opportunities Across Campus: The Effects of Cognitive Training and Entrepreneurial Passion on the Business Opportunity Prototype by Sílvia F. Costa, Susana C. Santos, Dominika Wach, and António Caetano.

Costa, Santos, Wach, and Caetano argue that institutions can best achieve the goals of entrepreneurship education with programs that focus on cognitive training to develop entrepreneurial mindsets and experiential learning methods that are relevant to the students. In addition, the authors argue that passion for entrepreneurship will have positive effects on learning in cognitive training programs. The quasi-experimental approach of this paper is interesting. The sample consists of students from different scientific study fields and colleges in Portugal and Germany. The students participated in learning tasks that involve active experimentation, concrete experience, and abstract conceptualization of viable business opportunities. Passion was measured beforehand for the students in the experimental and control groups using the Cardon et al. (2012) 13-item scale. The study results demonstrate that a relationship exist between cognitive training, individual affective variables, and opportunity recognition. The authors suggest that the study provides evidence of competencies to recognize opportunities that can be developed through entrepreneurship education.

\section{From Student to Entrepreneur: How Mentorships and Affect} Influence Student Venture Launch by Mujtaba Ahsan, Congcong Zheng, Alex DeNoble, and Martina Musteen.

This paper investigates the impact of mentorship and affect on student venture launch. The Social Cognitive Theory of Self-Regulation is employed to develop and present a two-stage model of how mentor relationships and founder affective state impacts entrepreneurial identity and venture success. Their model provides suggests that a high level of both founder affect and mentor relationships leads to more successful launches. They analyzed case studies and entrepreneur interviews to derive their suggestions. 
The Moderating Role of National Culture in the Relationship between University Entrepreneurship Offerings and Student Start-up Activity: An Embeddedness Perspective by Galina Shirokova, Tatyana Tsukanova, and Michael H. Morris.

The paper marries the contexts of universities with national culture to better understand the impact of these contexts upon entrepreneurial behavior among students. Via an embeddedness perspective, the study takes a deep dive into curricular issues and their relation to start-up activity across 26 different countries.

At least two interesting findings emerged. First, culture matters. Not surprisingly, individuals from different cultures respond to different courses, materials, and delivery styles. Educators should be aware, particularly those educators who are engaging students in cultures different from their own. For example, in more collectivist contexts, educators may want to take more of a team approach. Second, curriculum-especially experiential curriculum-matters. Increased start-up activity is associated with curricula which facilitated a more experiential experience. Also, a more co-curricular or strategic approach matters. That is, simply increasing the number of courses offered will help, but the real impact occurs when courses across the university are synthesized to offer a comprehensive experience.

\section{Entrepreneurship Unleashed: Understanding Entrepreneurial Education Outside of the Business School by Tobin Turner and Peter Gianiodis.}

Turner and Gianiodis tackle the growing trend of blending entrepreneurial program designs that merge entrepreneurial curriculum with a technical degree. Locating blended programs outside of traditional business school settings provides access to targeted student populations and faculty expertise. Because of cross-campus silos on the institution and department levels, however, curriculum integration of blended entrepreneurial programs can be difficult to implement and impact on student learning can be negative. For the most part, prior studies have focused little attention on students in blended entrepreneurial programs navigate institutional tensions. In this regard, the authors shift the focus focal point of our conversation about blended 
entrepreneurial programs from structural and environmental considerations to the roles played by the traits of individual program participants.

Using survey data collected from current students and recent graduates from a blended entrepreneurial program, the authors investigate whether entrepreneurial passion increases the likelihood of the students forming entrepreneurial intentions. In the context of blended entrepreneurship programs, the authors hypothesize that entrepreneurial passion is positively associated with scanning and search and entrepreneurial intention. The authors also hypothesize and test other interesting relationships between scanning and search, association and connection, evaluation and judgment, and entrepreneurial intention in the context of blended entrepreneurial programs.

From the study findings, the authors advise curriculum designers in technical degree programs to factor the individual attributes of students if the goal is to impact the entrepreneurial intentions of the students. They then introduce a model that evaluates how programs with different mission, goals, endowed resources, and other distinguishing factors can impact the propensity of students with different individual attributes to be alert to opportunities.

\section{Determinants of Graduates' Start-ups Creation Across a Multi- Campus Entrepreneurial University: The Case of Monterrey Institute of Technology and Higher Education by Maribel} Guerrero, David Urbano, James A. Cunningham, and Eduardo Gajón.

This paper investigates the individual and university determinants of graduate start-ups. While extant research has studied determinants of start-ups in modern economies, there is very little research in transitional economies. Utilizing a multi-campus university in a country with a transitional economy, they tested a model with 11,569 graduates from 30 different campuses. The authors investigated the role of prior experiences, skills/knowledge acquired at the university, economic aspirations, prior access to university incubation programs, the existence of university research parks, and accelerators on graduate start-ups. They found that a combination of prior experiences and skills/knowledge significantly impacted start-ups. Additionally, the study found that university support programs such as incubators, 
accelerators, and research parks have only a modest affect on graduate start-up activity.

\section{Contributing Forces in Entrepreneurship Research: A Global} Citation Analysis by Nianhang Xu, Yining Chen, Anna Fung, and Kam C. Chan.

This paper takes a novel look at research (and researchers) in the field of entrepreneurship with a special focus on international collaboration and geographic diversity. This study has important implications for entrepreneurship scholars as we consider research "everywhere." While readers will be drawn the ranking of scholars and universities, the impactful findings are those that instruct us to collaborate across universities and across countries. Indeed, the highest quality research is conducted by coauthors who are geographically dispersed. While we all strive to increase our individual output and the output of our universities, we must remember to also strive to increase value for the field, as it benefits all of us. And this likely best done via collaboration. Future research should continue to advance this work to better understand the boundary conditions under which these resources compliment, substitute or diminish each other in the contexts of both entrepreneurship theory development and entrepreneurship curriculum design.

The editor team for this special issue wishes to thank the authors who responded in a timely manner to our revision requests and produced quality research that should add to the foundational knowledge of understanding entrepreneurship across campus, across communities and across cultures. Additionally, we want to thank our reviewers who responded quickly to our requests and were very developmental in their reviews. Finally,we wish to thank the JSBM home office for their support in producing this special issue. 


\section{References}

Baumol, W. (1990). "Entrepreneurship: Productive, Unproductive, and Destructive," Journal of Political Economy 98(5), 893-921.

Cardon, M. S., M. D. Foo, D. Shepherd, and J. Wiklund (2012). "Exploring the Heart: Entrepreneurial Emotion Is a Hot Topic," Entrepreneurship Theory and Practice 36(1), 1-10.

Fetsch, E. (2015). "Are Incubators Beneficial to Emerging Businesses?," Growthology: Exploring Entrepreneurship Research, March 2. Available at http://www.kauffman.org/blogs/growthology/2015/03/ are-incubators-beneficial-to-emerging-businesses

Hobbs, R. J., L. M. Hallett, P. R. Ehrlich, and H. A. Mooney (2011). "Intervention Ecology: Applying Ecological Science in the Twenty-First Century," BioScience 61(6), 442-450.

Kauffman Foundation (2015). State of Entrepreneurship Address. Available from: http://www.kauffman.org/ /media/kauffman_org/resources/2015/soe/2015 state_of_entrepreneurship_address.pdf

Schumpeter, J. (1942). "Creative Destruction," in Capitalism, Socialism and Democracy. Ed. J. Schumpeter. New York: Harper and Row, 82-85.

Tornatzky, L. G., and E. C. Rideout (2014). Innovation U 2.0: Reinventing University Roles in a Knowledge Economy. Available from: http://www. innovation-u.com/InnovU-2.0 rev 